\title{
Epidemiology and long-term prognosis of atrial fibrillation in rural African patients
}

\author{
Dakaboué Germain Mandi ${ }^{1,6^{*}}$, Joel Bamouni ${ }^{2}$, Dangwé Temoua Naïbé ${ }^{3}$, Rélwendé Aristide Yaméogo ${ }^{4}$, \\ Elisé Kaboré ${ }^{1}$, Yibar Kambiré ${ }^{5}$, Koudougou Jonas Kologo ${ }^{5,6}$, Georges Rosario Christian Millogo 5,6, \\ Nobila Valentin Yaméogo ${ }^{5,6}$, Anna Thiam Tall ${ }^{5,6}$ and Patrice Zabsonré $e^{5,6}$
}

\begin{abstract}
Background: Few studies have addressed the pattern of atrial fibrillation (AF) in rural Africa. The purpose of the study was to assess the epidemiology and long-term prognosis of AF in rural African patients in the Regional Hospital Center (RHC) of Tenkodogo, Burkina Faso.

Results: Overall, 107 of 1805 cardiac cases presented with AF (prevalence of 5.9\%). Six patients were excluded. Mean age was $66.56 \pm 14.92$ years, and $53.47 \%$ were female. Hypertension was the most prevalent cardiovascular risk factor (59.41\%). Congestive heart failure (HF) was reported in $85.15 \%$ of the study patients at presentation. Most of the study population presented with severe underlying heart disease (93.1\%), and hypertensive heart disease was the most prevalent with $45.54 \%$ of the cases. The mean $\mathrm{CHA}_{2} \mathrm{DS}_{2} \mathrm{VASC}$ score in patients with non-valvular heart disease $(n=91)$ was $3.33 \pm 1.25$ (extremes $1-6)$ while the risk of bleeding was low (HAS-BLED score $\leq 1)$ in 82 patients (81.2\%). Oral anticoagulation was prescribed in few cases (5.26\%). During a follow-up period of $74.43 \pm$ 23.94 weeks, acute HF and stroke occurred in respectively 43 and 6 patients. Forty-one patients (40.59\%) died. The overall survival rate was $69 \%$ at 6-month and $59.4 \%$ at 1-year follow-up. Patients with idiopathic dilated cardiomyopathy were at higher risk of death than other patients (log-rank test $=11.88, p<0.001$ ) over time.

Conclusion: AF is not rare in rural African patients and is associated with an increased long-term risk of HF, stroke, and mortality.
\end{abstract}

Keywords: Atrial fibrillation, Epidemiology, Anticoagulation, Morbidity, Mortality, Africa

\section{Background}

Sub-Saharan Africa (SSA) is facing an epidemiological transition with an exponential increase of non-communicable diseases particularly cardiovascular ones such as atrial fibrillation (AF). AF is the most common sustained arrhythmia in clinical practice occurring in patients with a variety of cardiovascular and non-cardiac conditions, rising in incidence with patient age to affect nearly one quarter of the adult population over their lifetime [1-3]. Its prevalence is globally increasing $[2,3]$. Hospitalbased studies revealed that the prevalence of AF in SSA is ranging from 4.6 to $10.6 \%$ [4-7]. AF is strongly

\footnotetext{
*Correspondence: mandi_germain@yahoo.fr

${ }^{1}$ Cardiology Unit, Department of General Medicine, Regional Hospital Center of Tenkodogo, Tenkodogo, Burkina Faso

${ }^{6}$ Department of cardiology, Teaching Hospital of Yalgado Ouedraogo,

Ouagadougou, Burkina Faso

Full list of author information is available at the end of the article
}

associated with an increased morbidity, such as stroke/ systemic embolism or heart failure [8-11], and high risk of mortality $[2,11]$. Healthcare systems in SSA are also characterized by limitations in human and financial resources and geographical access [12]. Data on AF in Burkina are scarce and only available for urban centers. Therefore, the present study aimed to assess the longterm prognosis of AF in rural Africans in the Eastern Center region of Burkina Faso, Western Africa.

\section{Patients and methods}

This prospective cohort study was conducted in the cardiology unit of the department of medicine of the Regional Hospital Center (RHC) of Tenkodogo, Tenkodogo, Burkina Faso. The RHC of Tenkodogo is the tertiary healthcare center that covers a dry orchard savannah region populated of about 1.4 million inhabitants, almost 
constituted by subsistence farmers. Tenkodogo, the capital town of this eastern-center region, is located at $188 \mathrm{~km}$ from Ouagadougou, the political capital town of the country. Since the opening of the RHC, the first cardiologist was assigned in 2015. So far, there is no established national health insurance in Burkina Faso and the easterncenter region makes no exception. Therefore, care costs are most of the time supported by family network. At the time of recruitment, the cardiology unit was provided with only the basic equipment such as 12-lead electrocardiogram (ECG) and transthoracic echocardiography. Ambulatory (Holter) electrocardiogram, stress test, and coronary angiography were not available. International normalized ratio (INR) was not also performed at the site and was only available at Ouagadougou.

Patients aged over 18 years attending the cardiology unit who had a documented AF on 12-lead electrocardiogram (ECG) and consented to participate were consecutively enrolled in the study from 1 January 2015 to 30 December 2016. Patients' sociodemographic data (age, gender, socioeconomic level) were recorded. Lower socioeconomic status was defined as an average income $<2$ US dollar per day [13]. Cardiovascular risk factors (hypertension, mellitus diabetes, dyslipidemia, smoking, obesity, alcohol use), anthropometric parameters, signs, and symptoms were collected. Patient's serum creatinine, glucose, uric acid, ions, and hemoglobin were measured and thyroid hormones checked when clinically indicated. Two-dimensional and Doppler transthoracic echocardiography was used for the diagnosis of underlying heart disease. Left ventricular ejection fraction was measured using Simpson biplane formula [14]. We did not classify AF into its different types (new onset, paroxysmal, persistent, and permanent) due to lack of previously recorded ECGs at the time of presentation. Lone AF refers to episodes of AF in patients younger than 65 years without clinical and echocardiographic evidence of underlying cardiac disease.

In practice, the diagnosis of hypertensive heart disease was based on the presence of echocardiogram abnormalities such as left ventricular hypertrophy (concentric or eccentric), increased left ventricular mass index, enlarged left ventricular or left atrial size, and increased volumes, and diastolic or systolic left ventricular dysfunction in patients with hypertension apart from obvious alternative explanation. Ischemic heart disease was diagnosed in patients with either history of typical angina or acute myocardial infarction, and/or typical ECG abnormalities of acute myocardial infarction or myocardial ischemia, plus ventricular regional wall motion abnormality on $2 \mathrm{D}$ echocardiography. Valvular heart disease diagnosis was based on joint ESC/EACTS guidelines on the management of valvular heart disease [15]. Restrictive cardiomyopathy was considered in the presence of normal or reduced diastolic volumes (of one or both ventricles), normal or reduced systolic volumes, and normal ventricular wall thickness [16] as shown in Fig. 1. Idiopathic dilated cardiomyopathy was considered in the presence of left ventricular dilatation and left ventricular systolic dysfunction in the absence of abnormal loading conditions (hypertension, valve disease), coronary artery disease, congenital heart disease, or any obvious clinical condition sufficient to cause global systolic impairment. Right ventricular dilation and dysfunction may be present but are not necessary for the diagnosis [16].

The $\mathrm{CHA}_{2} \mathrm{DS}_{2}$ VASc score was used to stratify the thrombo-embolic risk in patients with non-valvular heart disease (VHD), both rheumatic and degenerative. The risk was low for a score of 0 , intermediate for a score of 1-2, and high for a score $>2$ [17]. The hemorrhagic risk was assessed in all patients using HAS-BLED score. This risk was low for a score $\leq 1$, intermediate for a score of $2-3$, and high for a score $\geq 4$ [18]. Prescribed medications were also assessed.

Patients were followed up until 30 June 2017. Outcomes of interest were ischemic stroke, heart failure (HF), and death. The immediate cause of death was also recorded.

Data were analyzed using Epi info 7 version 3 and $R$ software. Continuous variables were expressed as means \pm standard deviation (SD) and categorical variables as percentage. Differences between groups were assessed using chi-square or Student test as appropriate. Survival curves were performed using the Kaplan-Meier method and log-rank test used for comparison. A value of $p<$ 0.05 was considered statistically significant.

\section{Results}

During the recruitment period, 1805 patients attended the cardiology unit (both outpatients and inpatients). AF was found in 107 patients accounting for $5.9 \%$ of all admissions. Six patients were excluded from the final analysis process (uncomplete data 04, lost to follow-up 02). Of the remaining 101 patients, 47 were male (46.53\%) and 54 were female (53.47\%). Their mean age was $66.56 \pm 14.92$ years (extremes 20-99 years). Most of the study patients were of low socioeconomic condition (89.11\%). Hypertension was the most prevalent cardiovascular risk factor (59.41\%). Congestive HF was reported in $85.15 \%$ of the study patients at presentation (Table 1).

Underlying heart disease was found in 94 patients (93.1\%). Hypertensive heart disease was present in $45.54 \%$ of the cases. Mean left ventricular ejection fraction (LVEF) was $41 \% \pm 17$. HF with reduced ejection fraction (LVEF < 40\%) was reported in 60 patients (Table 2). 

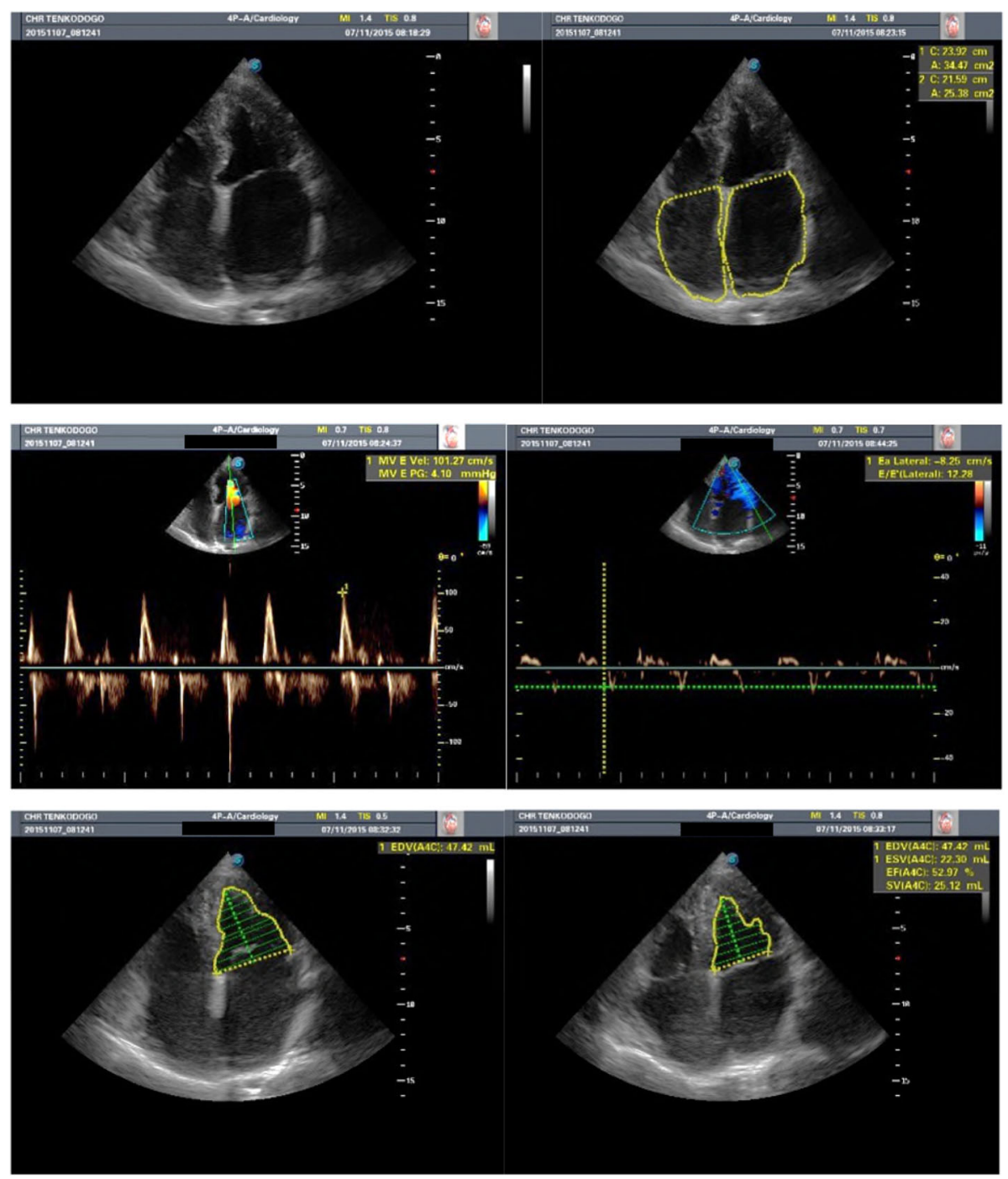

Fig. 1 Echocardiogram revealing restrictive cardiomyopathy in a 78-year-old woman with atrial fibrillation. Note the reduction of both ventricles' volumes, normal left ventricle (LV) wall thickness and massive bi-atrial enlargement in apical four-chamber views. The LV ejection fraction was slightly reduced with evidence of diastolic dysfunction

Patients with non-VHD accounted for $90.1 \%(n=$ 91) of all study patients. Their mean age was 68.73 years versus 46.90 years in patients with VHD $(p<$ $0.001)$. Valvular heart diseases comprised rheumatic $(n=6)$ and degenerative $(n=4)$ ones. The mean $\mathrm{CHA}_{2} \mathrm{DS}_{2}$ VASc score on non-VHD patients was $3.33 \pm 1.25$ (extremes 1-6). Their risk of thrombo-embolism was intermediate $\left(\mathrm{CHA}_{2} \mathrm{DS}_{2}\right.$ VASc score of $1-$ 2 ) in 25 of 91 patients (27.5\%) and high $\left(\mathrm{CHA}_{2} \mathrm{DS}_{2-}\right.$ VASc score $>2$ ) in 66 of this subgroup (72.5\%).

The mean HAS-BLED score was $0.95 \pm 0.68$ (extremes 0-3) for the all study population. The risk of bleeding was low (HAS-BLED score $\leq 1$ ) in 82 patients $(81.2 \%)$ and intermediate in 19 patients with a HAS-BLED score of $2-3$.
Antiarrhythmic drugs were prescribed in 73 of 101 patients (72.28\%). Amiodarone was used in 31 patients (30.69\%) and digoxin in 40 patients (39.60\%). None of the study patients underwent an electrical cardioversion. Anticoagulation was initiated with enoxaparin in 25 patients. Vitamin $\mathrm{K}$ antagonist (VKA) was prescribed in 4 of the 76 patients $(5.26 \%)$ at high risk of stroke and/or systemic thrombo-embolism (66 patients with nonvalvular $\mathrm{AF}$ and 10 patients with VHD). Antiplatelet agents were prescribed in 84 of 101 patients $(83.17 \%)$. Angiotensin-converting enzyme inhibitors/angiotensin receptor blockers were used in 94 patients for the treatment of underlying conditions (Table 3 ).

The mean follow-up period was $74.43 \pm 23.94$ weeks (extremes 42-116 weeks). At the time of the last follow- 
Table 1 Clinical baseline characteristics of the study population

\begin{tabular}{|c|c|}
\hline Characteristic & Value \\
\hline Age (years), mean $\pm S D$ & $66.56 \pm 14.92$ \\
\hline Female, $n(\%)$ & $54(53.47)$ \\
\hline Low socioeconomic level, $n$ (\%) & $90(89.11)$ \\
\hline \multicolumn{2}{|l|}{ Cardiovascular risk factors } \\
\hline Hypertension, $n$ (\%) & $60(59.41)$ \\
\hline Diabetes, $n(\%)$ & $07(6.90)$ \\
\hline Smoking, $n(\%)$ & $29(28.71)$ \\
\hline Dyslipidemia, $n$ (\%) & $04(3.96)$ \\
\hline Alcohol abuse, $n$ (\%) & $12(11.88)$ \\
\hline Body mass index $\left(\mathrm{kg} / \mathrm{m}^{2}\right)$, mean $\pm \mathrm{SD}$ & $21.63 \pm 3.17$ \\
\hline Obesity (body mass index $\geq 30 \mathrm{~kg} / \mathrm{m}^{2}$ ), $n(\%)$ & $3(2.97)$ \\
\hline Heart rate (beats/minute), mean \pm SD & $108.99 \pm 29.08$ \\
\hline Systolic blood pressure $(\mathrm{mmHg})$, mean \pm SD & $126.12 \pm 28.89$ \\
\hline Diastolic blood pressure $(\mathrm{mmHg})$, mean $\pm \mathrm{SD}$ & $76.73 \pm 16.25$ \\
\hline \multicolumn{2}{|l|}{ Signs and symptoms } \\
\hline Congestive heart failure, $n(\%)$ & $86(85.15)$ \\
\hline Palpitations, n (\%) & $59(58.42)$ \\
\hline Chest pain, $n(\%)$ & $30(29.70)$ \\
\hline
\end{tabular}

up visit, 8 patients (7.92\%) were in sinus rhythm. During the follow-up period, 45 patients $(44.6 \%)$ were readmitted (43 patients for acute decompensation of heart failure associated with ischemic stroke in 4 cases and 2 cases of isolated ischemic stroke). No hemorrhagic complication was reported. Forty-one patients (40.59\%) died. The overall survival rate was $69 \%$ at 6-month and $59.4 \%$ at 1-year follow-up. Patients with idiopathic dilated cardiomyopathy were at higher risk of death than other patients (log-rank test $=11.88, p<0.001$ ) over time (Fig. 2). The mean age of deceased patients was $70.90 \pm$ 15.36 years compared to those who survived with a mean age of $63.60 \pm 13.98$ years $(p=0.015)$. Twenty-nine of the 45 readmissions $(64.44 \%)$ versus 12 of the readmission-free group $(21.43 \%)$ died $(p<0.001)$. The immediate cause of death was ischemic stroke $(n=4)$, acute decompensation of heart failure $(n=28)$, and sudden death defined as death that occurred unexpectedly in an otherwise stable patient within $1 \mathrm{~h}$ of the onset of symptoms $(n=9)$.

\section{Discussion}

This present prospective cohort study was the first one to provide a hospital-based prevalence of AF (5.9\%) in rural Burkina Faso. Previous studies in SSA have reported comparable findings however in urban populations $[5,6,19]$. In a rural Ghana, AF was reported to be scarce in a traditional African community accounting for $0.3 \%$ of 924 individuals aged of 50 years and above [20].
Table 2 Laboratory baseline findings and underlying heart diseases of the study population

\begin{tabular}{|c|c|}
\hline Parameter & Value \\
\hline Serum glucose $(\mathrm{mmol} / \mathrm{l})$, mean $\pm \mathrm{SD}$ & $4.68 \pm 1.31$ \\
\hline Hemoglobin $(\mathrm{g} / \mathrm{dl})$, mean \pm SD & $11.74 \pm 1.97$ \\
\hline Serum creatinine $(\mu \mathrm{mol} / \mathrm{l})$, mean $\pm \mathrm{SD}$ & $123.1 \pm 56.48$ \\
\hline eGFR $\left(\mathrm{ml} / \mathrm{min} / 1.73 \mathrm{~m}^{2}\right)$, mean $\pm \mathrm{SD}$ & $61.67 \pm 24.66$ \\
\hline Uric acid $(\mu \mathrm{mol} / \mathrm{l})$, mean $\pm \mathrm{SD}$ & $387.81 \pm 101.54$ \\
\hline Serum potassium $(\mathrm{mmol} / \mathrm{l})$, mean $\pm \mathrm{SD}$ & $3.97 \pm 0.49$ \\
\hline Serum calcium $(\mathrm{mmol} / \mathrm{l})$, mean $\pm \mathrm{SD}$ & $2.1 \pm 0.23$ \\
\hline Sodium $(\mathrm{mmol} / \mathrm{l})$, mean $\pm \mathrm{SD}$ & $135.55 \pm 8.28$ \\
\hline QRS duration (milliseconds), mean \pm SD & $110.35 \pm 9.28$ \\
\hline Left bundle block branch, $n$ (\%) & $13(12.87)$ \\
\hline Left atrium diameter $(\mathrm{mm})$, mean $\pm \mathrm{SD}$ & $46.04 \pm 7.06$ \\
\hline Left atrium surface $\left(\mathrm{cm}^{2}\right)$, mean $\pm S D$ & $23.73 \pm 6.50$ \\
\hline $\operatorname{LVEF}(\%)$, mean \pm SD & $41.4 \pm 17$ \\
\hline LVEF $<40 \%, n(\%)$ & $60(59.41)$ \\
\hline LVEF $=40-49 \%, n(\%)$ & $9(8.91)$ \\
\hline LVEF $\geq 50 \%, n(\%)$ & $32(31.68)$ \\
\hline Left ventricular filling pressure $\left(E / E^{\prime}\right)$, mean $\pm S D$ & $14.68 \pm 4.65$ \\
\hline Left ventricular diastolic dysfunction, $n$ (\%) & $75(74.26)$ \\
\hline \multicolumn{2}{|l|}{ Heart diseases and etiologies } \\
\hline Hypertensive heart disease, $n(\%)$ & $46(45.54)$ \\
\hline Idiopathic dilated cardiomyopathy, n (\%) & $21(20.79)$ \\
\hline Valvular heart disease, $n(\%)$ & $10(9.90)$ \\
\hline Restrictive cardiomyopathy, $n$ (\%) & $8(7.92)$ \\
\hline Ischemic heart disease, $n(\%)$ & $6(5.94)$ \\
\hline Hyperthyroidism, n (\%) & $3(2.97)$ \\
\hline Lone AF, n (\%) & $7(6.90)$ \\
\hline
\end{tabular}

$S D$ standard deviation, eGFr estimated glomerular filtration rate using CKD-EPI formula, $L V E F$ left ventricular ejection fraction, $A F$ atrial fibrillation

In developing countries, patients with AF seem to be a decade younger and more likely to have heart failure [21]. The mean age of our patients was $66.56 \pm 14.92$ years and is similar to that of Ntep-Gweth et al. [22] in Cameroon with $65.8 \pm 13$ years. Conversely, most studies in SSA reported more younger age below 60 years $[4-6,23]$. It is well known that the risk of AF increases with age and is higher in patients with cardiovascular diseases and cardiovascular risk factors such as hypertension, diabetes mellitus, obesity, smoking, and alcohol abuse [24]. The majority of our AF patients had severe structural heart disease (93.1\%) with hypertensive heart disease being the most prevalent and that is consistent with findings from SSA $[5,6,22]$. Hypertension was the most common risk factor of AF (59.41\%) as stated by previous reports [4, 22, 25-27].

As SSA population lifespan is growing substantially, cardiovascular risk factors, particularly hypertension, are expected to significantly increase in the forthcoming 
Table 3 Distribution of study patients according to drug treatment

\begin{tabular}{|c|c|}
\hline Drug & Value \\
\hline \multicolumn{2}{|l|}{ Antiarrhythmics } \\
\hline Amiodarone, $n(\%)$ & $31(30.69)$ \\
\hline Betablockers, n (\%) & $17(16.83)$ \\
\hline Digoxin, $n(\%)$ & $40(39.60)$ \\
\hline Calcium channel blockers, $n$ (\%) & $02(1.98)$ \\
\hline Amiodarone + digoxin, $n(\%)$ & $11(10.89)$ \\
\hline \multicolumn{2}{|l|}{ Antithrombotics } \\
\hline Enoxaparin, $n(\%)$ & $25(24.75)$ \\
\hline Vitamin $\mathrm{K}$ antagonist*, $n(\%)$ & $4(5.26)$ \\
\hline Antiplatelet agents, $n$ (\%) & $84(83.17)$ \\
\hline ACEI/ARB, $n(\%)$ & $94(93.07)$ \\
\hline Spironolactone, $n(\%)$ & $63(62.38)$ \\
\hline Thiazides, $n$ (\%) & $9(8.91)$ \\
\hline Loop diuretics, $n$ (\%) & $86(85.15)$ \\
\hline Nitrates, $n$ (\%) & $55(54.46)$ \\
\hline Statins, n (\%) & $6(5.94)$ \\
\hline
\end{tabular}

Loop diuretics and nitrates were used during the acute phase of congestive heart failure

$A C E I / A R B$ angiotensin-converting enzyme inhibitors/angiotensin receptor blockers

*Four over 76 patients at high risk of stroke received VKA decades. Consequently, there is a great need to set up strategies of prevention, treatment, and control of hypertension. Congestive HF is often the mode of presentation of AF and was highly prevalent in our cohort with $85.15 \%$. In a prospective cohort study of 172 patients with AF conducted in Cameroon [22], congestive HF was reported in $58 \%$ of the cases. Idiopathic dilated cardiomyopathy was found to be the second most frequent underlying heart disease $(20.8 \%)$ in our work. However, cardiac magnetic resonance and coronary angiography could definitely discriminate between ischemic and non-ischemic origins of this subset of dilated cardiomyopathy. Moreover, specific molecular and genetic testing should be part of the etiological diagnostic workup, as they may offer specific therapeutic opportunities [28], but they are costly for low-income countries. VHD was less frequent in our study (9.9\%) compared with previous findings in SSA [4, 22]. Our low frequency of VHD could be explained by the poor outcome of such disease which is more prevalent in younger people. Consequently, their life expectancy could have been shortened especially in a context where cardiac surgery is so far not available.

In the present report, most patients had a high risk of stroke and systemic thrombo-embolism (66 patients with non-valvular AF and 10 patients with VHD) and should be prescribed oral anticoagulation (OAC) for the prevention of stoke and/or systemic embolism. Furthermore, their bleeding risk was low in the majority of the cases allowing safer anticoagulation. Only $5.26 \%$ of
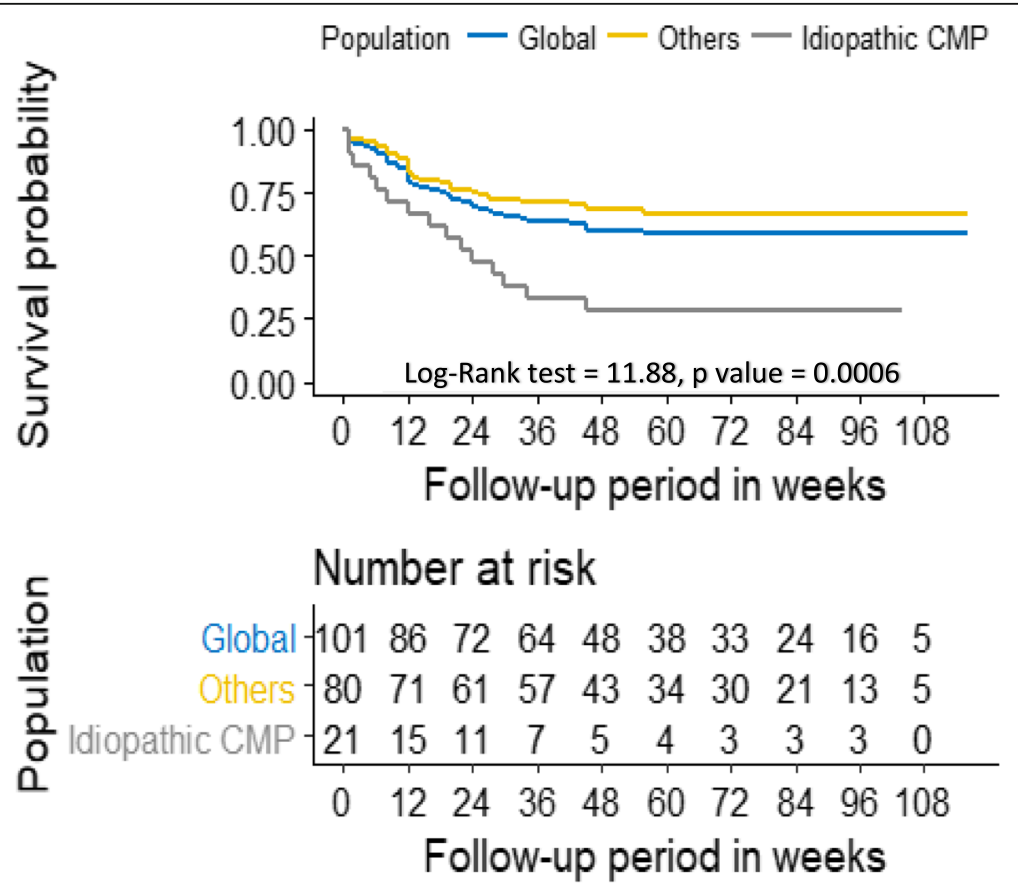

Fig. 2 Kaplan-Meier survival curves for all population and patients stratified by the presence and absence of idiopathic cardiomyopathy (CMP) 
patients who should benefit from OAC received VKA. The OAC prescription rate in patients with AF is very contrasting but globally low in SSA [4, 7, 11, 22, 23, 29] compared with data from Europe with over $80 \%$ of eligible patients being anticoagulated [30]. Constraints on OAC prescription in our site comprised financial aspects, difficulties in monitoring INRs, particularly geographic access. Consequently, only few patients who were able to regularly travel to Ouagadougou (round trip by bus costs $\approx 8$ US Dollar) could afford this biological test as most of our study patients were known to live in poor conditions. Hence, the OAC prescription rate may have been impeded leading to low physician adherence to the guidelines. Therefore, monitoring VKA treatment (INRs) should be made available and cost-effective for remote areas in SSA. It has been shown that some patients refused the initiation of VKA treatment because of repeated blood sampling for INR checks and related (nutritional diet and possible bleeding) aspects [7]. Moreover, direct oral anticoagulants are effective, have no mandatory monitoring of INRs, and could be an alternative to VKA but these are still costly for African patients. Aspirin which was widely used in our cohort $(83.17 \%)$ is neither effective nor safe and has very limited indications [31].

In the present cohort study, the long-term mortality was very high $(40.59 \%)$ and much higher than that observed by Ntep-Gweth et al. [22] with 29.5\%. The RELY-AF Registry reported the 1-year mortality and stroke in patients from 47 countries. Over 15,000 patients were enrolled and 1750 (11\%) died within 1 year. The mortality rate was significantly higher by 1 year in South America (17\%) and Africa (20\%) compared with North America, Western Europe, and Australia $(10 \%, p<0.001)$ [32]. By the end of the follow-up, ischemic stroke occurred in 6 of our patients (5.94\%). Data from Africa have shown rates of 8 to $12.5 \%$ at 1 year compared with $3 \%$ in the developed world [22, 32]. Heart failure is generally the most common cause of death [32] and was reported as adverse event in 43 patients (42.6\%) in the present work. Higher rates of adverse outcomes in our cohort are likely due to the low rate of $\mathrm{OAC}$ and the fact that these patients tend to present for cardiology care at certainly advanced stages of the underlying heart disease and thereby increasing the probability of severe complications such as heart failure and stroke and life-threatening ventricular arrhythmias.

Our study had some limitations. Undoubtedly, only patients from a privileged background who could afford cardiologist care and/or those with an advanced stage of heart disease were included. We only recruited patients attending the cardiology unit with severe cardiac diseases and therefore those with less symptomatic cardiovascular diseases or asymptomatic AF in non-cardiac units and in the community may have been excluded.
Furthermore, ambulatory (Holter) ECG recording was not performed in this study for the diagnosis of silent and/or paroxysmal AF. Comparison of patients with AF to the whole population $(n=1805)$ for prognosis was not performed due to lack of data. Despite the underestimation of the burden of the disease, this work provided somewhat the spectrum of AF and highlighted the anticoagulation challenge in rural Africa.

\section{Conclusion}

Atrial fibrillation is not rare in rural African patients and is associated with an increased long-term risk of heart failure, stroke, and mortality. Its management is challenging in rural SSA. We urged that INR check should be made available as cardiology expertise is now spreading through remote areas of Africa. It is also of great need to early detect and treat modifiable risk factors to reduce the burden of AF. Further studies are needed, particularly population-based ones, in order to characterize in deep, the spectrum of AF in this area.

\section{Abbreviations \\ AF: Atrial fibrillation; ECG: Electrocardiogram; eGFR: Estimated glomerular filtration rate; HF: Heart failure; INR: International normalized ratio; LVEF: Left ventricular ejection fraction; OAC: Oral anticoagulation; RHC: Regional Hospital Center; SD: Standard deviation; SSA: Sub-Saharan Africa; \\ VHD: Valvular heart disease; VKA: Vitamin K antagonist}

\section{Acknowledgements}

We are grateful to subjects enrolled in this study for their participation. Many thanks to the staff members of the Department of General Medicine of the Regional Hospital Center of Tenkodogo for their technical support during the study.

\section{Authors' contributions}

DGM, JB, RAY, and DTN conceived and designed the study protocol. DGM, JB RAY, DTN, and EK conducted the patients' enrolment, data collection, and follow-up work. PZ supervised all the processes. DGM and RAY performed the statistical analyses and drafted the manuscript. JB and DTN contributed to the data acquisition. YK, KJK, GRCM, NVY, ATT, and PZ critically revised the manuscript. All authors read and approved the final manuscript.

\section{Funding}

This study was not funded.

\section{Availability of data and materials}

The dataset supporting the results and conclusions of this article will be available from the corresponding author on request.

\section{Ethics approval and consent to participate}

Ethical approval was obtained from the RHC of Tenkodogo Ethics committee by 31 December 2014. The Ethics Committee waived the need for written informed consent due to illiteracy of most study participants and noninvasive aspect of collected data obtained from routine practice. Only verbal informed consent was required from all study participants. The study was carried out in accordance with the Declaration of Helsinki.

Consent for publication

Not applicable

Competing interests

The authors declare that they have no competing interests. 


\section{Author details}

${ }^{1}$ Cardiology Unit, Department of General Medicine, Regional Hospital Center of Tenkodogo, Tenkodogo, Burkina Faso. ${ }^{2}$ Superior School of Health Sciences, University of Ouahigouya, Ouahigouya, Burkina Faso. ${ }^{3}$ Faculty of Human Health Sciences, University of N'Djamena, N'Djamena, Chad. ${ }^{4}$ University of Normandie, UNIHAVRE- UNIROUEN - UNICAEN, CNRS, UMR IDEES, Le Havre, France. ${ }^{5}$ Training and Research Unit of Health Sciences, University Ouaga I - Professeur Joseph Ki-Zerbo, Ouagadougou, Burkina Faso. ${ }^{6}$ Department of cardiology, Teaching Hospital of Yalgado Ouedraogo, Ouagadougou, Burkina Faso.

Received: 20 May 2019 Accepted: 16 July 2019 Published online: 05 September 2019

\section{References}

1. Miyasaka Y, Barnes ME, Gersh BJ et al (2006) Secular trends in incidence of atrial fibrillation in Olmsted County, Minnesota, 1980 to 2000, and implications on the projections for future prevalence. Circulation 114:119125. https://doi.org/10.1161/CIRCULATIONAHA.105.595140

2. Chamberlain AM, Gersh BJ, Alonso A et al (2015) Decade-long trends in atrial fibrillation incidence and survival: a community study. Am J Med 128 : 260-267.e1. https://doi.org/10.1016/j.amjmed.2014.10.030

3. Chugh SS, Havmoeller R, Narayanan K et al (2013) Worldwide epidemiology of atrial fibrillation: a Global Burden of Disease 2010 Study. Circulation 129: 837-847. https://doi.org/10.1161/CIRCULATIONAHA.113.005119

4. Sliwa K, Carrington MJ, Klug E et al (2010) Predisposing factors and incidence of newly diagnosed atrial fibrillation in an urban African community: insights from the Heart of Soweto Study. Heart 96:1878-1882. https://doi.org/10.1136/hrt.2010.206938

5. Coulibaly I, Anzouan-Kacou JB, Kouao Konin C et al (2010) Fibrillation auriculaire: épidémiologie à l'Institut de cardiologie d'Abidjan (Côte d'Ivoire). Médecine Trop 70:371-374

6. Kandem F, Ba H, Kandem M et al (2017) Epidemiologic aspects of atrial fibrillation in a tertiary hospital in a sub-Saharan Africa setting. Open Access Libr J 04:e3384. https://doi.org/10.4236/oalib.1103384

7. Yameogo AR, Kologo JK, Mandi G et al (2016) Use of vitamins K antagonists in non-valvular atrial fibrillation thromboembolic risk prevention in Burkina Faso. Pan Afr Med J 24:108. https://doi.org/10.11604/pamj.2016.24.108.7100

8. Stewart S, Hart CL, Hole DJ et al (2002) A population-based study of the long-term risks associated with atrial fibrillation: 20-year follow-up of the Renfrew/Paisley study. Am J Med 113:359-364. https://doi.org/10.1016/ S0002-9343(02)01236-6

9. Singer DE, Chang Y, Borowsky LH et al (2013) A new risk scheme to predict ischemic stroke and other thromboembolism in atrial fibrillation: the ATRIA study stroke risk score. J Am Heart Assoc 2:e000250. https://doi.org/10.1161/ JAHA.113.000250

10. Koton S, Schneider ALC, Rosamond WD et al (2014) Stroke incidence and mortality trends in US communities, 1987 to 2011. JAMA 312:259-268. https://doi.org/10.1001/jama.2014.7692

11. Mandi D, Samadoulougou A, Yameogo R et al (2015) Non-valvular atrial fibrillation related ischaemic stroke at the teaching hospital of Yalgado Ouedraogo, Burkina Faso. J Vasc Med Surg 3:171. https://doi.org/10.41 72/2329-6925.1000171

12. Stambler BS, Ngunga LM (2015) Atrial fibrillation in Sub-Saharan Africa: epidemiology, unmet needs, and treatment options. Int J Gen Med 8:231. https://doi.org/10.2147/IJGM.S84537

13. Ferreira FHG, Chen $\mathrm{S}$, Dabalen $\mathrm{AL}$, et al. A global count of the extreme poor in 2012: data issues, methodology and initial results. The World Bank 2015. http://documents.worldbank.org/curated/en/3600214681 87787070/A-global-count-of-the-extreme-poor-in-2012-data-issuesmethodology-and-initial-results

14. Lang MR, Badano PL, Mor-Avi V et al (2015) Recommendations for cardiac chamber quantification by echocardiography in adults: an update from the American Society of Echocardiography and the European Association of Cardiovascular Imaging. J Am Soc Echocardiogr 28:39.e14

15. Vahanian A, Alfieri O, Andreotti F et al (2012) Guidelines on the management of valvular heart disease (version 2012). Eur Heart J 33:24512496. https://doi.org/10.1093/eurheartj/ehs109

16. Elliott $P$, Andersson B, Arbustini E et al (2008) Classification of the cardiomyopathies: a position statement from the European Society Of
Cardiology Working Group on Myocardial and Pericardial Diseases. Eur Heart J 29:270-276. https://doi.org/10.1093/eurheartj/ehm342

17. Lip GYH, Nieuwlaat R, Pisters R et al (2010) Refining clinical risk stratification for predicting stroke and thromboembolism in atrial fibrillation using a novel risk factor-based approach: the Euro Heart Survey on atrial fibrillation. Chest 137:263-272. https://doi.org/10.1378/chest.09-1584

18. Pisters R, Lane DA, Nieuwlaat R et al (2010) A novel user-friendly score (HAS-BLED) to assess 1-year risk of major bleeding in patients with atrial fibrillation: the Euro Heart Survey. Chest 138:1093-1100. https://doi.org/1 0.1378/chest.10-0134

19. Sliwa K, Wilkinson D, Hansen C et al (2008) Spectrum of heart disease and risk factors in a black urban population in South Africa (the Heart of Soweto Study): a cohort study. Lancet 371:915-922. https://doi.org/10.1016/S0140-6 736(08)60417-1

20. Koopman JJ, van Bodegom D, Westendorp RG et al (2014) Scarcity of atrial fibrillation in a traditional African population: a community-based study. BMC Cardiovasc Disord 14:87. https://doi.org/10.1186/1471-2261-14-87

21. Oldgren J, Healey JS, Ezekowitz $M$ et al (2014) Variations in cause and management of atrial fibrillation in a prospective registry of 15,400 emergency department patients in 46 countries: the RE-LY Atrial Fibrillation Registry. Circulation 129:1568-1576. https://doi.org/10.1161/ CIRCULATIONAHA.113.00545

22. Ntep-Gweth M, Zimmermann M, Meiltz A et al (2010) Atrial fibrillation in Africa: clinical characteristics, prognosis, and adherence to guidelines in Cameroon. EP Eur 12:482-487. https://doi.org/10.1093/europace/euq006

23. Mbaye A, Pessinaba S, Bodian M et al (2010) La fibrillation atriale, fréquence, facteurs étiologiques, évolution et traitement dans un service de cardiologie de Dakar, Sénégal. Pan Afr Med J 6:16

24. Schnabel RB, Yin X, Gona P et al (2015) 50 year trends in atrial fibrillation prevalence, incidence, risk factors, and mortality in the Framingham Heart Study: a cohort study. Lancet 386:154-162. https:// doi.org/10.1016/S0140-6736(14)61774-8

25. Rahman F, Kwan GF, Benjamin EJ (2014) Global epidemiology of atrial fibrillation. Nat Rev Cardiol 11:639-654. https://doi.org/10.1038/nrcardio.2014.118

26. Shavadia J, Yonga G, Mwanzi S et al (2013) Clinical characteristics and outcomes of atrial fibrillation and flutter at the Aga Khan University Hospital, Nairobi. Cardiovasc J Afr 24:6-9. https://doi.org/10.5830/CVJA-2012-064

27. Nieuwlaat R, Capucci A, Camm AJ et al (2005) Atrial fibrillation management: a prospective survey in ESC Member Countries: the Euro Heart Survey on Atrial Fibrillation. Eur Heart J 26:2422-2434. https://doi. org/10.1093/eurheartj/ehi505

28. Rapezzi C, Arbustini E, Caforio ALP et al (2013) Diagnostic work-up in cardiomyopathies: bridging the gap between clinical phenotypes and final diagnosis. A position statement from the ESC Working Group on Myocardial and Pericardial Diseases. Eur Heart J 34:1448-1458. https://doi.org/10.1093/ eurheartj/ehs397

29. Temu TM, Lane KA, Shen C et al (2017) Clinical characteristics and 12-month outcomes of patients with valvular and non-valvular atrial fibrillation in Kenya. PLoS ONE 12. https://doi.org/10.1371/journal.pone.0185204

30. Kirchhof P, Ammentorp B, Darius H et al (2014) Management of atrial fibrillation in seven European countries after the publication of the 2010 ESC Guidelines on atrial fibrillation: primary results of the PREvention of thromboemolic events - European Registry in Atrial Fibrillation (PREFER in AF). Europace 16:6-14. https://doi.org/10.1093/europace/eut263

31. Ben Freedman S, Gersh BJ, Lip GYH (2015) Misperceptions of aspirin efficacy and safety may perpetuate anticoagulant underutilization in atrial fibrillation. Eur Heart J 36:653-656. https://doi.org/10.1093/eurheartj/ehu494

32. Healey JS, Oldgren J, Ezekowitz M et al (2016) Occurrence of death and stroke in patients in 47 countries 1 year after presenting with atrial fibrillation: a cohort study. Lancet 388:1161-1169. https://doi.org/10.1016/ S0140-6736(16)30968-0

\section{Publisher's Note}

Springer Nature remains neutral with regard to jurisdictional claims in published maps and institutional affiliations. 